\title{
Augmentative on-farm delivery methods for the parasitoid Habrobracon hebetor Say (Hymenoptera: Braconidae) to control the millet head miner Heliocheilus albipunctella (de Joannis) (Lepidoptera: Noctuidae) in Burkina Faso and Niger
}

\author{
Malick N. Ba • Ibrahim B. Baoua • Adama Kaboré • \\ Laouali Amadou • Nassirou Oumarou • \\ Clementine Dabire-Binso • Antoine Sanon \\ Received: 30 November 2013 / Accepted: 22 August 2014/Published online: 29 August 2014 \\ (C) International Organization for Biological Control (IOBC) 2014
}

\begin{abstract}
Augmentative on-farm delivery methods for the parasitoid Habrobracon hebetor (Say) (Hymenoptera: Braconidae) to control the millet head miner (MHM) Heliocheilus albipunctella (de Joannis) (Lepidoptera: Noctuidae) were investigated in Burkina Faso from 2011 to 2012 and in Niger in 2012. Our findings indicate that $7 \mathrm{~cm} \times 10 \mathrm{~cm}$ jute bags containing $50 \mathrm{~g}$ of millet grains, $30 \mathrm{~g}$ of millet flour, 25 Corcyra cephalonica larvae and two mated H. hebetor females are the most effective option for on-farm delivery of the parasitoid. The parasitoid progeny started emerging from the bags eight days after confinement and 57-71 parasitoid adults emerged
\end{abstract}

Handling Editor: Torsten Meiners.

M. N. Ba $(\bowtie)$

International Crops Research Institute for the Semi-Arid Tropics (ICRISAT), Niamey, BP 12404, Niamey, Niger e-mail: b.malick@cgiar.org

I. B. Baoua · L. Amadou · N. Oumarou University of Maradi/ Institut National de Recherche Agronomique du Niger (INRAN), Maradi, Niger

A. Kaboré - C. Dabire-Binso

Institut de l'Environnement et de Recherches Agricoles (INERA), Kamboinsé, Burkina Faso

A. Sanon

UFR/SVT, Université de Ouagadougou, Ouagadougou,

Burkina Faso from each bag. Using the methods we developed, over $90 \%$ parasitism of MHM larvae was achieved in millet farms. The implications of these findings for a large extension of MHM biocontrol program are discussed.

Keywords Millet head miner - Biological control . Habrobracon hebetor · Corcyra cephalonica

\section{Introduction}

In the Sahelian region of West Africa, pearl millet, Pennisetum glaucum (L.) R. Br., is a major cereal food crop. It is the only cereal crop adapted to this arid region. In addition to the extreme climatic conditions, the millet crop suffers from many constraints, including insect pests (Nwanze and Harris 1992). The millet head miner (MHM), Heliocheilus albipunctella (de Joannis) (Lepidoptera: Noctuidae), is the key insect pest of pearl millet in the Sahel region (Gahukar 1984). Damage to the crop is due to larvae that feed on the panicle and prevent grain formation (Ndoye 1991; Nwanze and Harris 1992). Typical yield losses range from 40 to $85 \%$ (Gahukar et al. 1986; Nwanze and Sivakumar 1990; Krall et al. 1995; Youm and Owusu 1998).

Different approaches, including cultural management, host plant resistance and use of pesticides, have been tested (Gahukar 1989, 1990a, b, 1992; Nwanze 
and Sivakumar 1990) with limited success and applicability (Nwanze and Harris 1992).

Biological control using the indigenous parasitoid wasp Habrobracon hebetor (Say) (Hymenoptera: Braconidae) appears promising (Gahukar et al. 1986; Bhatnagar 1987; Youm and Gilstrap 1993). In the earlier 1980s a natural parasitism of 64-95\% due to H. hebetor Say (Hymenoptera: Braconidae) was reported in Senegal and Niger (Gahukar et al. 1986; Bhatnagar 1987; Nwanze and Harris 1992). H. hebetor has been intensively studied because of its suitability as a biological control agent of stored product moths (Benson 1973; Rotary and Gerling 1973; Nikam and Pawar 1993; Antolin et al. 1995; Yu et al. 1999; Eliopoulos and Stathas 2008; Dabhi et al. 2011; Farag et al. 2012). Later on H. hebetor was known to occur as two biologically distinct (warehouse strain and field strain) but morphologically inseparable siblings (Heimpel et al. 1997).

The first experimental augmentative releases of $H$. hebetor for controlling the MHM were attempted in 1985 in Senegal (Bhatnagar 1989) followed by Niger in the early 2000s (Garba and Gaoh 2008). More recently, augmentative releases of $H$. hebetor were successfully carried out in Burkina Faso, Mali and Niger (Payne et al. 2011; Ba et al. 2013; Baoua et al. 2013). The parasitoids were released in $15 \mathrm{~cm} \times 25 \mathrm{~cm}$ jute bags containing $200 \mathrm{~g}$ of millet grains and $200 \mathrm{~g}$ of millet flour, together with 25 larvae of the rice moth Corcyra cephalonica (Stainton) (Lepidoptera: Pyralidae) and two mated $H$. hebetor females (Ba et al. 2013). The jute bags were suspended to the ceiling of traditional straw granaries and emerging parasitoids were able to escape through the jute mesh and straw granaries and disperse to parasitize MHM larvae in millet fields (Ba et al. 2013).

Although this biological control program was effective, there are still some limitations with regard to large-scale application, especially (i) place of deployment of jute bag for communities where granaries are made of clay, which could not enable parasitoids to escape, and (ii) in the quantity of millet flour/grain needed for formulating the parasitoid bags. Thus, we investigated the effects of placing jute bags directly within millet fields on the parasitism of MHM. Finally, we investigated the effects of reducing the jute bag size, and thus the content, on the emergence of offspring parasitoids from the bags and their parasitism of MHM in the field.

\section{Materials and methods}

Insect cultures

Since $H$. albipunctella is a univoltine species diapausing from October to June (Gahukar et al. 1986), a colony of $H$. hebetor was established and maintained in the laboratory on an alternate host, the rice moth $C$. cephalonica. Both insects were reared in the laboratory under ambient conditions. Both insect colonies were established from wild insects collected in 2011 from each of the countries. H. hebetor were collected from the field and $C$. cephalonica from stored products. C. cephalonica rearing technique was adapted from that developed by Bal et al. (2002). Wooden cages $(20 \times 20 \times 13 \mathrm{~cm})$ with muslin cloth on three lateral sides and wood at the bottom were used for C. cephalonica mass rearing. A mixture of $1.2 \mathrm{~kg}$ of millet flour and $1.8 \mathrm{~kg}$ of millet grains was introduced into the cages and inoculated with approximately 3,000 C. cephalonica eggs. Subsequent generations were regularly obtained after 30 days at room temperature (average $26{ }^{\circ} \mathrm{C}$ ). Third and fourth instar C. cephalonica larvae were used for the mass rearing of $H$. hebetor. For this purpose, $25 C$. cephalonica larvae were confined within a Petri dish for $48 \mathrm{~h}$ with two mated $H$. hebetor females. The subsequent generation of $H$. hebetor emerged 7-14 days after confinement.

\section{Effect of bag size on parasitoid emergence}

This experiment was carried out in Burkina Faso and Niger. In Burkina Faso, the experiment was conducted in the laboratory of "Institut de l'Environemment et de Recherche Agricole" in Dori, under a fluctuating temperature of $24-35{ }^{\circ} \mathrm{C}$ with $57-77 \%$ relative humidity. In Niger, the experiment was performed in the laboratory of "Institut National de Recherche Agricole du Niger" in Maradi under a fluctuating temperature of $30-37{ }^{\circ} \mathrm{C}$ with $50-70 \%$ relative humidity.

The experiment was set with four replicates and two treatments as follows: (i) Treatment 1: Jute bags of $15 \mathrm{~cm} \times 25 \mathrm{~cm}$ containing $200 \mathrm{~g}$ of millet grains, $100 \mathrm{~g}$ of millet flour, $25 \mathrm{C}$. cephalonica larvae (a mixture of third and fourth instar larvae) and two mated $H$. hebetor females. (ii) Treatment 2: Jute bags of $7 \mathrm{~cm} \times 10 \mathrm{~cm}$ containing $50 \mathrm{~g}$ of millet grains, 
$30 \mathrm{~g}$ of millet flour, 25 C. cephalonica larvae (mixture of third and fourth instar larvae) and two mated $H$. hebetor females. All the bags were covered with muslin cloth to trap the emerging parasitoids. For each treatment, a set of 20 bags was used and each batch of five bags represented one replicate. The bags were kept in the lab for one month and emerging parasitoids were sexed, counted and removed daily. After one month, the bags were emptied and any living or dead insects were recorded.

Effect of deploying parasitoid bags within millet fields on parasitism

This experiment was performed in 2011 and 2012 in Northern Burkina Faso. The research sites belong to the Sahel agroecological zone, which has an unimodal rainfall pattern, and the rainy season lasts from June to September. Total rainfalls of 446 and $593 \mathrm{~mm}$ were recorded in 2011 and 2012, respectively. This experiment was carried out with jute bags of $15 \mathrm{~cm} \times 25 \mathrm{~cm}$ containing $200 \mathrm{~g}$ of millet grains, $100 \mathrm{~g}$ of millet flour, $25 \mathrm{C}$. cephalonica larvae (a mixture of third and fourth instar larvae) and two mated $H$. hebetor females. Parasitoid bags were deployed within the millet farm and attached to the top of a 2-m-tall wooden stick fixed in the soil and roofed with a calabash (one half of a dried shell of gourd) to avoid direct rainfall. Three bags were attached together per farm at the centre of the farm. In each village the bags were evenly distributed within five millet farms ( 3 bags per farm), one in the centre of the village and one in each direction (E, W, N and S). Typical villages have a diameter of $1 \mathrm{~km}$, each of $\mathrm{E}$, $\mathrm{W}, \mathrm{N}$ and $\mathrm{S}$ farm was $500 \mathrm{~m}$ away from the farm in the centre of the village. Selected villages have endemic occurrences of the MHM with over $60 \%$ infested panicles (Ba et al. 2010; Baoua et al. 2013). Six villages were selected every year for the experiment. New villages different from 2011 were selected in 2012. The selected villages were separated by $5 \mathrm{~km}$ based on preliminary studies demonstrating that the parasitoid $H$. hebetor can travel up to $5 \mathrm{~km}$ from the release point (Garba and Gaoh 2008). However, control villages, where no parasitoid releases were made, were at least $10 \mathrm{~km}$ away from villages receiving the parasitoids. The experimental design includes two treatments: (i) three villages each supplied with 15 parasitoid bags and ii) three control villages that did not receive any parasitoid bags.

Data on MMH parasitism by $H$. hebetor were recorded 30 days after releases. For this purpose, 500 millet panicles were randomly selected in each village from five millet farms (100 panicles per farm) and dissected. The number of living (not parasitized) and parasitized larvae was recorded. The larvae parasitized by $H$. hebetor are easily distinguished by the presence of cocoons (Garba and Gaoh 2008).

Effect of bag size on field parasitism

This experiment was performed during 2012 in Burkina Faso and Niger. In both countries, research sites belong to the same above described Sahel agroecological zone. In 2012, total rainfalls of 623 and $593 \mathrm{~mm}$ were recorded at the research sites in Burkina Faso and Niger, respectively. In both countries, the experimental design included three treatments: (i) two villages each supplied with 15 small jute bags $(7 \mathrm{~cm} \times 10 \mathrm{~cm})$; (ii) two villages each supplied with 15 large jute bags $(15 \mathrm{~cm} \times 25 \mathrm{~cm})$; and (iii) two control villages that did not receive any parasitoid bags. As describe above the villages receiving parasitoids were separated by $5 \mathrm{~km}$ and control villages, where no parasitoid releases were made, were at least $10 \mathrm{~km}$ away from villages receiving the parasitoids. For villages receiving the parasitoids bags, the bags were deployed within the millet farm and attached to the top of a 2-m-tall wooden stick fixed in the soil. The same arrangement as above was used for deployment of bags within villages and individual farms.

Data on MMH parasitism by $H$. hebetor were recorded 30 days after releases. For this purpose, 500 millet panicles were randomly selected in each village from five millet farms (100 panicles per farm) and dissected. The number of living (not parasitized) and parasitized larvae was recorded.

Data analysis

Field data were subjected to ANOVA (PROC GLM) using SAS software version 8 (SAS 2001). When ANOVAs were significant, means were separated by the Student-Newman-Keuls test at the $5 \%$ level. Laboratory data were subjected to a $t$ test to compare emerging parasitoids from the two sizes of jute bags. 

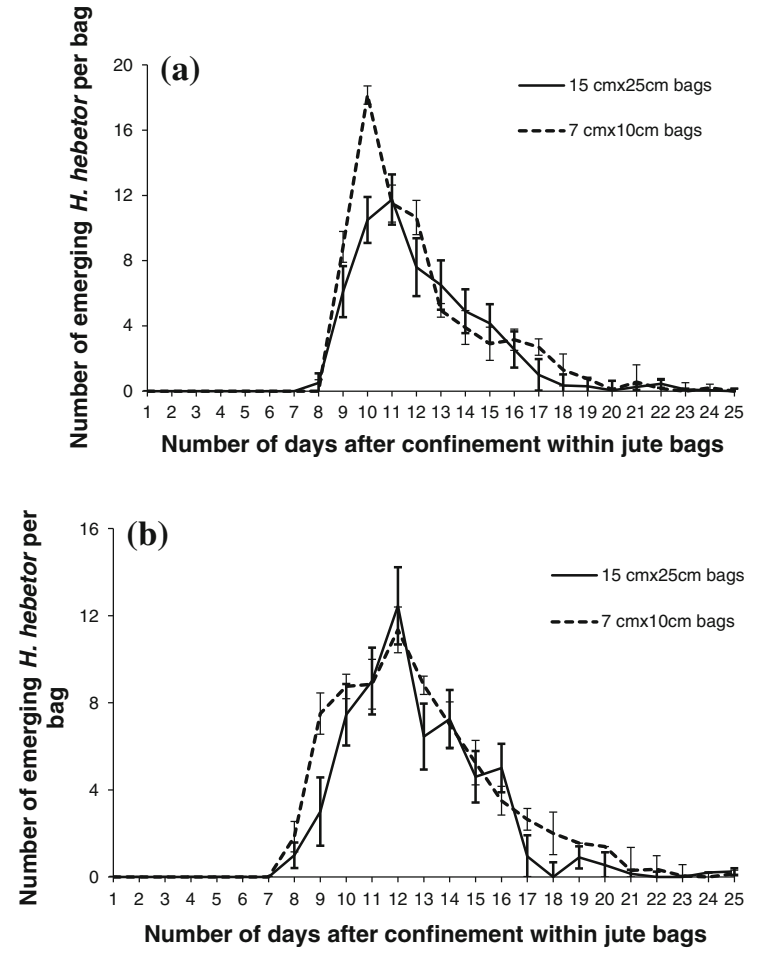

Fig. 1 Daily emergence of Habrobracon hebetor (Say) progeny (Mean \pm SE) after confinement within different sizes of jute bags in the laboratory in Burkina Faso (a) and Niger (b)

Percentages of parasitism data were arcsine transformed prior to statistical tests.

\section{Results}

Effect of bag size on parasitoid emergence

Parasitoid progeny began emerging from the bags eight days after confinement and greater than $91 \%$ of the parasitoids emerged within 16 days in Burkina Faso (Fig. 1a) and Niger (Fig. 1b). H. hebetor developed within less than 13 days on average (Table 1). Regardless of the country, the total number of emerging parasitoids did not significantly differ between the two sizes of jute bags (Table 1). In both countries, a maximum of almost 70 parasitoid offspring emerged from the bags (Table 1). The sex ratio of the emerging $H$. hebetor parasitoids was malebiased regardless of the jute bag's size (Table 1). $H$. hebetor females parasitized up to $95 \%$ of the $C$. cephalonica larvae within the jute bags (Table 1).
Effect of deploying parasitoid bags within millet fields on parasitism

The releases of the parasitoids in millet field significantly increased the natural parasitism of MHM (Fig. 2). In both years, the parasitism by $H$. hebetor was significantly higher in villages where the parasitoid bags were placed than the control villages (2011: $\mathrm{F}=15.30 ; \quad$ df $=1, \quad 28 ; \quad P=0.0007 ; \quad 2012$ : $\mathrm{F}=54.32 ; \mathrm{df}=1,28, P=0.0003)$.

Effect of bag size on field parasitism

Regardless of the size of jute bag, the release of the parasitoids significantly increased the natural parasitism of MHM (Fig. 3). In both countries, the parasitism by $H$. hebetor was significantly higher in villages where the $7 \times 10 \mathrm{~cm}$ parasitoid bags were placed (Burkina Faso: $\mathrm{F}=221.71$; $\mathrm{df}=2,28 ; P<0.0001$; Niger: $\mathrm{F}=131.59$; $\mathrm{df}=2,28 ; P<0.0001)$.

\section{Discussion}

Our findings clearly demonstrate that the $7 \times 10 \mathrm{~cm}$ jute bags delivered the same number of parasitoids as the $15 \times 25 \mathrm{~cm}$ bags. With the small bag $40 \%$ of millet grain/flour is saved per bag. The two H. hebetor females parasitized more than $80 \%$ of $C$. cephalonica larvae within the jute bags. This is much higher than reported by Magro and Parra (2001) with C. cephalonica and $H$. hebetor. The results suggested by the former authors were achieved with a ratio of one $H$. hebetor female for 40 host larvae whereas our study used 12 host larvae. As reported by Schöller (2000) differences may be explained by the host-parasitoid ratio.

In general, the parasitoids began emerging eight days after confinement of $H$. hebetor females with $C$. cephalonica larvae. This is in line with findings of Garba and Gaoh (2008). Over $91 \%$ of the parasitoid offspring emerged within 16 days. The average development time was around 12 days and this is consistent with previous findings with $C$. cephalonica larvae (Magro and Parra 2001). Considering the parasitoids reproductive potential at least 1,000 parasitoids can be released in each village within 12 days when using 15 jute bags per village. With the rapid development time of $H$. hebetor combined with the 
Table 1 Number of emerging Habrobracon hebetor (Say) parasitoids, their sex ratio, and the percentage (\%) of Corcyra cephalonica (Stainton) larvae parasitized in relation to the size of the jute bags

\begin{tabular}{|c|c|c|c|c|c|}
\hline Countries & Bag size & $\begin{array}{l}\text { Number } \\
\text { parasitoids emerged } \\
(\text { Mean } \pm \mathrm{SE})\end{array}$ & $\begin{array}{l}\text { H. hebetor } \\
\text { proportion } \\
(\% \text { female } \pm \mathrm{SE})\end{array}$ & $\begin{array}{l}\% \text { Parasitism } \\
\text { C. cephalonica } \\
(\text { Mean } \pm \mathrm{SE})\end{array}$ & $\begin{array}{l}\text { H. hebetor development } \\
\text { time (Mean } \pm \mathrm{SE})\end{array}$ \\
\hline Burkina & $25 \times 15 \mathrm{~cm}$ & $57.10 \pm 5.01$ & $38.58 \pm 4.64$ & $80.77 \pm 0.17$ & $12.15 \pm 0.34$ \\
\hline Faso & $10 \times 7 \mathrm{~cm}$ & $\begin{array}{l}69.80 \pm 5.57 \\
t=-1.69 \\
\mathrm{df}=38 \\
P=0.10\end{array}$ & $\begin{array}{l}41.08 \pm 3.18 \\
t=-0.44 \\
\mathrm{df}=38 \\
P=0.66\end{array}$ & $\begin{array}{l}87.19 \pm 0.08 \\
t=-1.72 \\
\mathrm{df}=38 \\
P=0.09\end{array}$ & $\begin{array}{l}11.64 \pm 0.31 \\
t=-1.08 \\
\mathrm{df}=118 \\
P=0.27\end{array}$ \\
\hline Niger & $\begin{array}{l}25 \times 15 \mathrm{~cm} \\
10 \times 7 \mathrm{~cm}\end{array}$ & $\begin{array}{l}59.20 \pm 8.98 \\
71.30 \pm 6.26 \\
t=-1.10 \\
\mathrm{df}=38 \\
P=0.27\end{array}$ & $\begin{array}{l}30.07 \pm 2.72 \\
24.11 \pm 2.58 \\
t=-1.59 \\
\mathrm{df}=38 \\
P=0.12\end{array}$ & $\begin{array}{l}95.36 \pm 0.16 \\
78.14 \pm 0.17 \\
t=4.60 \\
\mathrm{df}=38 \\
P<0.0001\end{array}$ & $\begin{array}{l}12.63 \pm 0.32 \\
12.80 \pm 0.36 \\
t=0.34 \\
\mathrm{df}=127 \\
P=0.73\end{array}$ \\
\hline
\end{tabular}

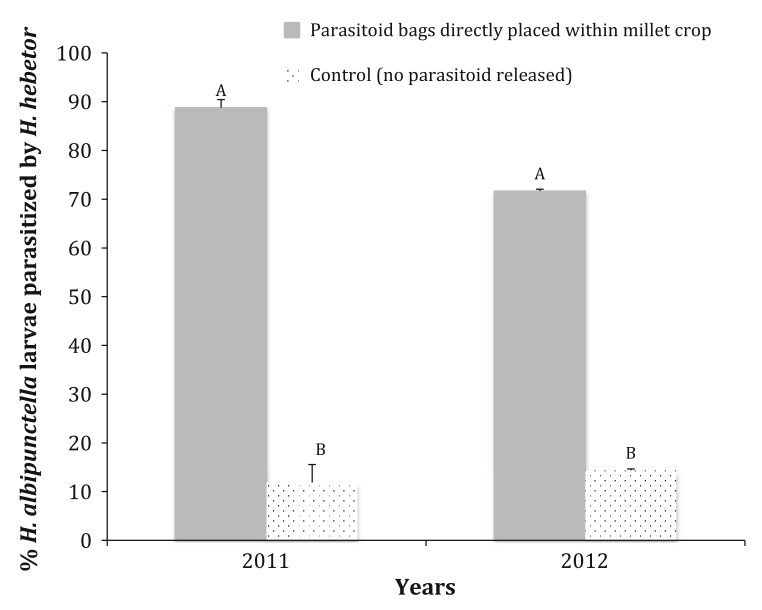

Fig. 2 Parasitized larvae of $H$. albinpuctella $(\%$ Mean + SE) due to $H$. hebetor, in villages covered by direct releases of $H$. hebetor within millet farms and control villages in Burkina Faso in 2011 and 2012. (For each year, means were compared by a Student-Newman-Keuls test at the $5 \%$ level, with different alphabetic letters indicating significant differences)

high rate of population growth (Youm and Gilstrap 1993; Nikam and Pawar 1993), we estimate that the set of 15 parasitoid bags per village can lead to parasitoid population buildup of up to several thousand parasitoids within four weeks.

The emerging offspring was male-biased regardless of bag size. Contrasting findings have been reported regarding the $H$. hebetor sex ratio with some studies reporting a male-biased sex ratio (Nikam and Pawar 1993; Gündüz and Gülel 2005; Eliopoulos and Stathas 2008; Landge et al. 2009) and others a female-biased

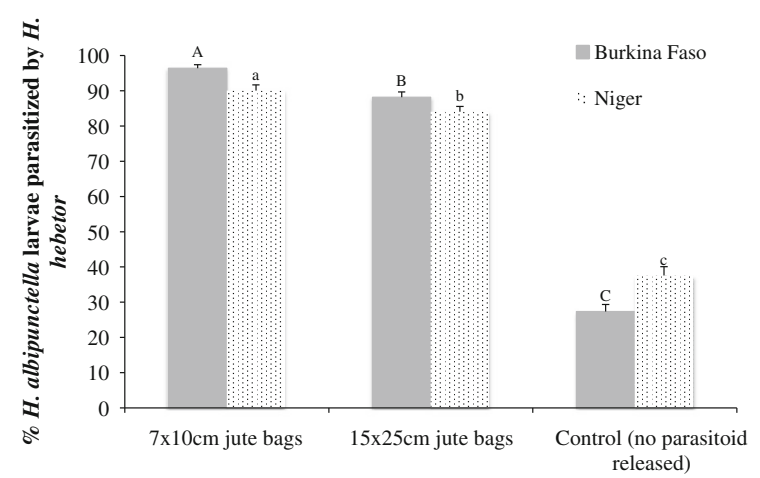

Fig. 3 Heliocheilus albipunctella (de Joannis) larvae (\% Mean + SE) parasitized by Habrobracon hebetor (Say) in villages in Burkina Faso and Niger participating in augmentative releases of $H$. hebetor in 2012 using different sizes of jute bags and control villages (Means were compared by a StudentNewman-Keuls test at the $5 \%$ level with different alphabetic letters indicating significant differences. Upper-case letters were used for Burkina Faso and lower-case letters were used for Niger)

sex ratio (Yu et al. 1999; Ghimire and Phillips 2010; Farag et al. 2012). These conflicting reports on $H$. hebetor progeny sex ratio are likely due to differences in the host larvae used, host larval stages, hostparasitoid ratio and environmental conditions (Whiting and Anderson 1932; Benson 1973; Rotary and Gerling 1973; King 1987; Ode et al. 1996; Yu et al. 2003; Dabhi et al. 2011). Likewise the male-biased sex ratio could be due to unfavourable rearing conditions. As demonstrated by Heimpel et al. (1997) the storagestrain of $H$. hebetor performed poorly on the field 
insect pest. In our case we reared the "field strain" of $H$. hebetor on larvae of $C$. cephalonica, a storage pest which may actually have been unfavorable and resulted in a male-biased sex ratio in the bags. Also as hypothesized by Antolin et al. (1995) H. hebetor male-biased sex ratios are probably linked to singlelocus complementary sex determination caused by a combination of diploid male viability and low allele diversity at the sex locus.

On-farm findings clearly suggest that the deployment of parasitoid bags within millet fields is effective for controlling MHM with up to $85 \%$ larvae parasitized. This is in line with previous augmentative releases of $H$. hebetor from straw granaries (Ba et al. 2013). In addition the small parasitoid bag is more effective than the big bag leading to over $90 \%$ of MHM larvae parasitized. Moreover, the smaller bag requires $40 \%$ less millet grains and flour per bag. This is a clear indication of use of small bags for biological control program.

Despite the already substantial natural parasitism due to $H$. hebetor (up to $38 \%$ in control villages), the augmentative release of $H$. hebetor significantly increased the mortality of MHM. The H. hebetor stored-product strain has been commercially used in Germany, Austria and the USA since the late 1990s for the biocontrol of warehouse insects (Brower et al. 1996; Schöller 2001). Outdoor releases of field strain of $H$. hebetor have been effective for controlling the cotton bollworm Helicoverpa armigera in Iran (Navaei et al. 2002). In India mass releases of $H$. hebetor have been successful for suppression of coconut head caterpillar Opisina arenosella (Desai et al. 2007).

In the Sahel MHM typically infested over $60 \%$ of millet panicle and leads to $53 \%$ yield losses (Baoua et al. 2013). Our findings confirm again the effectiveness of augmentative releases of $H$. hebetor for controlling MHM (Ba et al. 2013; Baoua et al. 2013) and as recently demonstrated effective parasitism by $H$. hebetor reduced grain losses from infested panicles by $34 \%$ (Baoua et al. 2013). Although releases of $H$. hebetor give a good control of the MHM, the parasitoid only attacks 3rd and later instar larvae of MHM when some damage to millet panicles has already occurred. Since indigenous egg parasitoids Trichogramma spp. are observed parasitizing MHM eggs (Ndoye and Gahukar 1995; Bal 1993) they could be tested for a more effective/early control of MHM.

Even though the effective augmentative release of braconid parasitoids has been demonstrated elsewhere
(Sivinski et al. 1996; Montoya et al. 2000; Wang et al. 2013), the wide use of this approach is still challenging (van Lenteren 2012). Particularly in the Sahel region, the parasitoid has a very limited chance of survival during the long dry season because of the scarcity of vegetation and alternate hosts. Thus, the biological control program will involve repeated releases of parasitoids every year. The numbers required are beyond the production capacity and mandates of research laboratories. To safeguard the sustainability of biological control program, it will be useful to investigate the feasibility of establishing a cottage industry to produce parasitoids. In that regard, we recommend that a feasibility study be conducted to assess economic viability of such an industry.

Acknowledgments This study was made possible through the support provided to INERA and INRAN by the Collaborative Crop Research Program (CCRP) of the McKnight Foundation under the terms of grants No. 09-036 thru 039. The opinions expressed herein are those of the authors and do not necessarily reflect the views of the CCRP/McKnight Foundation. The authors are also grateful to Maiga Djibey who helped selecting villages in Burkina Faso and our technicians Ouedraogo Theodore and Mayaki Gaya for data collection. We are also thankful to farmers who graciously allow collecting data in their millet field.

\section{References}

Antolin MF, Ode PJ, Strand MR (1995) Variable sex ratios and ovicide in an outbreeding parasitic wasp. Anim Behav 49:589-600

Ba NM, Dabire-Binso CL, Sanon A, Diallo B, Kabore A, Ouedraogo $T$ (2010) Integrated management of the millet head miner for enhancement of millet productivity in the Sahel. INERA's Internal Report, INERA, Kamboinse, Burkina Faso

Ba NM, Baoua IB, N'Diaye M, Dabire-Binso C, Sanon A, Tamò M (2013) Biological control of the millet head miner Heliocheilus albipunctella (de Joannis) (Lepidoptera: Noctuidae) in the Sahelian region by augmentative releases of the parasitoid wasp Habrobracon hebetor (Say) (Hymenoptera: Braconidae): effectiveness and farmers' perceptions. Phytoparasitica 41: $569-576$

Bal AB (1993) Etude du parasitisme naturel d'Heliocheilus albipunctella de Joannis (Lepidoptere: Noctuidae) par Trichogrammatoidea sp. (Hymenoptere: Trichogrammatidae) a Bambey. Insect Sci Appl 14:221-223

Bal AB, Kogo S, Dankoulou A, Gagaré S (2002). Guide d'élevage et de lâchers de Habrobracon hebetor Say (Hymenoptera, Braconidae) parasitoïde de la chenille mineuse de l'épi de mil et de son hôte de substitution Corcyra cephalonica (Stainton) Lepidoptera, Pyralidae. Technical Document, AGRHYMET Centre, Niamey, Niger 
Baoua IB, Amadou L, Oumarou N, Payne W, Roberts JD, Stefanova K, Nansen C (2013) Estimating effect of augmentative biological control on grain yields from individual pearl millet heads. J Appl Entomol 138:281-288

Benson JF (1973) Intraspecific competition in the population dynamics of Bracon hebetor Say (Hymenoptera: Braconidae). J Anim Ecol 42:105-124

Bhatnagar VS (1987) Conservation and encouragement of natural enemies of insect pest in dry land subsistence farming: problem, progress and prospects in the Sahelian zone. Insect Sci Appl 8:791-795

Bhatnagar VS (1989) Lutte biologique contre la chenille mineuse de l'épi du mil. Sahel PV info 1/2: 5-8

Brower JH, Smith L, Vail PV, Flinn PW (1996) Biological control. In: Subramanyam B, Hagstrum DW (eds) Integrated management of insects in stored products. Marcel Dekker, New York, USA. pp 223-286

Dabhi MR, Korat DM, Aishnav PR (2011) Influence of temperature, relative humidity and photoperiod on the development of Bracon hebetor Say. Karnataka J Agric Sci 24:558-560

Desai VS, Nagwekar DD, Patil PD, Narangalkar AL (2007) Field evaluation of a larval parasite Bracon hebetor Say against coconut black headed caterpillar. J. Plantation Crops 35:188-189

Eliopoulos PA, Stathas GJ (2008) Life tables of Habrobracon hebetor (Hymenoptera: Braconidae) parasitizing Anagasta kuehniella and Plodia interpunctella (Lepidoptera: Pyralidae): effect of host density. J Econ Entomol 101:982-988

Farag MMA, Sayeda SA, El-Husseini MM (2012) Life history of Habrobracon hebetor Say (Hymenptera: Braconidae) parasitizing Cadra (Ephestia) cautella (Walker) (Lepidopera: Pyralidae) on dried date fruits. Egypt J Biol Pest Control 22:73-77

Gahukar RT (1984) Insect pests of pearl millet in West Africa: a review. Int J Pest Manage 30:142-147

Gahukar RT (1989) Pest and disease incidence in pearl millet under different plant density and intercropping patterns. Agric Ecosyst Environ 26:69-74

Gahukar RT (1990a) Sampling techniques, spatial distribution and cultural control of millet spike worm, Raghuva albipunctella (Noctuidae: Lepidoptera). Ann Appl Biol 117:45-50

Gahukar RT (1990b) Reaction of locally improved pearl millets to three insect pests and two diseases in Senegal. J Econ Entomol 83:2102-2106

Gahukar RT (1992) Effect of various fertilizers and rates on insect pest/pearl millet relationship in Senegal. Trop Agric (Trinidad) 69:149-152

Gahukar RT, Guèvremont TH, Bhatnagar VS, Doumbia YO, Ndoye M, Pierrard G (1986) A review of the pest status of the millet spike worm, Rhaguva albipunctella de Joanis (Noctuidae: Lepidoptera) and its management in the Sahel. Insect Sci Appl 7:457-463

Garba M, Gaoh NB (2008) Use of Habrobracon hebetor in biological control of Heliocheilus albipunctella pearl millet head miner. In: Proceedings of the 8th international conference on pests in Agriculture. AFPP, INRA, Montpellier, France. pp. 436-444
Ghimire MN, Phillips TW (2010) Mass rearing of Habrobracon hebetor Say (Hymenoptera: Braconidae) on larvae of the Indian meal moth, Plodia interpunctella (Lepidoptera: Pyralidae): effects of host density, parasitoid density, and rearing containers. J Stored Prod Res 46:214-220

Gündüz EA, Gülel A (2005) Investigation of fecundity and sex ratio in the parasitoid Bracon hebetor Say (Hymenoptera: Braconidae) in relation to parasitoid age. Turk J Zool 29:291-294

Heimpel GE, Antolin MF, Franqui R, Strand MR (1997) Reproductive isolation and genetic variation between two "strains" of Bracon hebetor (Hymenoptera: Braconidae). Biol Control 9:149-156

King BH (1987) Offspring sex ratios in parasitoid wasps. Q Rev Biol 62:367-396

Krall S, Youm O, Kogo SA (1995) Panicle insect pest damage and yield loss in pearl millet. In: Nwanze KF, Youm O (eds), Proceeding of an international consultative workshop on panicle insect pest of sorghum and millet. ICRISAT Sahelian Centre, Niamey, Niger. pp. 135-145

Landge SA, Wankhede SM, Gangurde SM (2009) Comparative biology of Bracon hebetor Say on Corcyra cephalonica Stainton and Opisina arenosella Walker. Int J Plant Protection 2:278-280

Magro SR, Parra JRP (2001) Biology of the ectoparasitoid Bracon hebetor Say, 1857 (Hymenoptera: Braconidae) on seven Lepidopteran species. Scientia Agricola 58:693-698

Montoya P, Liedo P, Benrey B, Cancino J, Barrera JF, Sivinski J, Aluja M (2000) Biological control of Anastrepha spp. (Diptera: Tephritidae) in mango orchards through augmentative releases of Diachasmimorpha longicaudata (Ashmead) (Hymenoptera: Braconidae). Biol Control 18:216-224

Navaei AN, Taghizadeh M, Javanmoghaddam H, Oskoo T, Attaran MR (2002) Efficiency of parasitoid wasps, Trichogramma pintoii and Habrobracon hebetor against Ostrinia nubilalis and Helicoverpa sp. on maize in Moghan. In: Proceedings of the 15th Iranian Plant Protecion Congress, Kermanshah, Iran. p. 193

Ndoye M (1991) Biologie et dynamique des populations de Heliocheilus albipunctella (De Joannis) ravageur de la chandelle de mil dans le Sahel. Sahel PV Inf 39:11-20

Ndoye M, Gahukar R (1995) Insect pests of pearl millet in West Africa and their control. In: Nwanze KF, Youm O (eds) Proceeding of an international consultative workshop on panicle insect pest of sorghum and millet. ICRISAT Sahelian Centre, Niamey, Niger. pp 195-205

Nikam PK, Pawar CV (1993) Life tables and intrinsic rate of natural increase of Bracon hehetor Say (Hym., Braconidae) population on Corcyra cephalonica Staint. (Lep., Pyralidae), a key parasitoid of Helicoverpa armigera Hbn. (Lep., Noctuidae). J Appl Entomol 115:210-213

Nwanze KF, Harris KM (1992) Insect pests of pearl millet in West Africa. Rev Agric Entomol 80:1133-1155

Nwanze KF, Sivakumar MVK (1990) Insect pests of pearl millet in Sahelian West Africa-II. Raghuva albipunctella De Joannis (Noctuidae, Lepidoptera): distribution, population dynamics and assessment of crop damage. Int $\mathrm{J}$ Pest Manage 36:59-65 
Ode PJ, Antolin MF, Strand MR (1996) Sex allocation and sexual asymmetries in intra-brood competition in the parasitic wasp Bracon hebetor. J Anim Ecol 65:690-700

Payne W, Tapsoba H, Baoua IB, Ba NM, N'Diaye M, DabireBinso C (2011) On-farm biological control of the pearl millet head miner: realization of 35 years of unsteady progress in Mali, Burkina Faso and Niger. Int J Agric Sust 9:186-193

Rotary N, Gerling D (1973) The influence of some external factors upon the sex ratio of Bracon hebetor Say (Hymenoptera: Braconidae). Environ Entomol 2:134-138

SAS (2001) SAS version 8 for Windows. SAS Institute, Cary, USA

Schöller M (2000) Forager in the rye: biological control of Ephestia elutella in bulk grain. IOBC/WPRS Bulletin 23(10):149-159

Schöller M (2001) Commercial application of parasitoids to control stored-product pests in Germany and Austria. In: Proceedings of the 1 st meeting of working group on biocontrol of arthropod pests in the stored products. pp. 29-32

Sivinski JM, Calkins CO, Baranowsky R, Harris D, Brambila J, Diaz J, Burns RE, Holler T, Dodson D (1996) Suppression of Caribbean fruit fly (Anastrepha suspensa (Loew) Diptera: Tephritidae) population through augmented releases of the parasitoid Diachasmimorpha longicaudata (Ashmead) (Hymenoptera: Braconidae). Biol Control 6:177-185

van Lenteren JC (2012) The state of commercial augmentative biological control: plenty of natural enemies, but a frustrating lack of uptake. BioControl 57:1-20

Wang XG, Levy K, Daane KM (2013) Evaluation of an indigenous parasitoid Habrobracon gelechiae (Hymenoptera: Braconidae) for biological control of light brown apple moth Epiphyas postvittana (Lepidoptera: Tortricidae) in California. Biocontrol Sci Technol 23:433-447

Whiting PW, Anderson RL (1932) Temperature and other factors concerned in male biparentalism in Habrobracon. Am Nat 66:420-432

Youm O, Gilstrap FE (1993) Life-fertility tables of Bracon hebetor Say (Hymenoptera: Braconidae) reared on $\mathrm{He}$ liocheilus albipunctella (De Joannis) (Lepidoptera: Noctuidae). Insect Sci Appl 14:455-459

Youm O, Owusu EO (1998) Assessment of yield loss due to the millet head miner, Heliocheilus albipunctella (Lepidoptera: Noctuidae) using a damage rating scale and regression analysis in Niger. Int $J$ Pest Manage 44:119-121

Yu S-H, Ryoo MI, Na JH (1999) Life history of Bracon hebetor (Hymenoptera: Braconidae) on Plodia interpunctella (Lepidoptera: Pyralidae) on a dried vegetable commodity. J Asia-Pacif Entomol 2:149-152
Yu S-H, Ryoo MI, Na JH, Choi WI (2003) Effect of host density on egg dispersion and the sex ratio of progeny of Bracon hebetor (Hymenoptera: Braconidae). J Stored Prod Res 39:385-393

Malick N. Ba is an entomologist at the International Crops Research Institute for the Semi-Arid Tropics (ICRISAT) in Niger. His current research is focusing on development and deployment of biological control and host plant resistance management options against millet, sorghum and legume major insect pests in the Sahel. On particular interest he is working on development of affordable and sustainable methods for rearing and releases the parasitoid wasp Habrobracon hebetor.

Ibrahim B. Baoua is an entomologist at University of Maradi, Niger. His main research interests comprise biological control, host plant resistance, and use of plant insecticides for controlling major insect pests of millet, legume and vegetables. For the past seven years he has coordinated a regional project on biological control of the millet head miner in Burkina Faso, Mali and Niger.

Adama Kaboré conducted the laboratory experiments in Burkina Faso as part of his MSc thesis. He is now enrolled in a $\mathrm{PhD}$ program at University of Ouagadougou, Burkina Faso. He is supervised by Antoine Sanon, Malick Ba and Clementine Dabire. His $\mathrm{PhD}$ project is on the use of Habrobracon hebetor for controlling the millet head miner.

Laouali Amadou is a research assistant at the Niger National Institute for Agricultural Research (INRAN) based in Maradi, Niger. He is working with Ibrahim Baoua on mass releases of $H$. hebetor for controlling the millet head miner.

Nassirou Oumarou conducted the on-farm experiments in Niger as part of his MSc thesis under Ibrahim Baoua supervision.

Clementine Dabire-Binso is an Agricultural entomologist with more than 30 years working experience on IPM of cereal and legume insect pests in the Sahel. She is leading the Institute of Environment and Agricultural Research (INERA) Central entomology laboratory based in Kamboinse, Burkina Faso.

Antoine Sanon is professor of Entomology and chair of the Laboratory of Entomology of Ouagadougou University, Burkina Faso. His research focussed on the relationship between insect pests and parasitoids 